\title{
The role of affective meaning, semantic associates, and orthographic neighbours in modulating the N400 in single words
}

\author{
Frida Blomberg, Mikael Roll, Johan Frid, \\ Magnus Lindgren, and Merle Horne ${ }^{2}$ \\ ${ }^{1}$ Linnæus University $\mid{ }^{2}$ Lund University
}

The N400 has been seen to be larger for concrete than abstract words, and for pseudowords than real words. Using a word vector analysis to calculate semantic associates (SA), as well as ratings for emotional arousal (EA), and a measure of orthographic neighbourhood (ON), the present study investigated the relation between these factors and $\mathrm{N} 400$ amplitudes during a lexical decision task using Swedish word stimuli. Four noun categories differing in concreteness: SPECIFIC (squirrel), GENERAL (animal) EMOTIONAL (happiness) and ABSTRACT (tendency) were compared with PSEUDOWORDS (danalod). Results showed that N400 amplitudes increased in the order EMOTIONAL < ABSTRACT $<$ GENERAL $<$ SPECIFIC $<$ PSEUDOWORD. A regression analysis showed that the amplitude of the N400 decreased the more semantic associates a word had and the higher the rating for emotional arousal it had. The $\mathrm{N} 400$ also increased the more orthographic neighbours a word had. Results provide support for the hierarchical organisation of concrete words assumed in lexical semantics. They also demonstrate how affective information facilitates meaning processing.

Keywords: concreteness, emotional arousal, semantic specificity, semantic associates, orthographic neighbours: ERP, N400, lexical decision, word vector

\section{Introduction}

The N400 and lexical properties

The event-related potential (ERP) N400 has repeatedly been shown to be more negative for concrete than abstract words (Barber, Otten, Kousta, and Vigliocco, 2013; Gullick, Mitra, and Coch, 2013; Kounios and Holcomb, 1994; Nittono, 
Suehiro, and Hori, 2002). However, our understanding of what determines this effect is still not complete. Several factors may contribute to concreteness-related differences in word processing, including linguistic semantic as well as neurocognitive ones. In order to shed more light on the mechanisms behind N400 concreteness effects, the present study, using data from Swedish, investigated N400 patterns for PSEUDOWORDs (e.g. kvup) and words from four noun categories differing in their concreteness-related semantic content: SPECIFIC (e.g. carrot), GENERAL (e.g. food), EMOTIONAL (e.g. love), ABSTRACT (e.g. idea).

Originally found for semantically anomalous endings in a sentence context, such as 'I take coffee with cream and dog' (Kutas and Hillyard, 1980), the N400 has also been shown to be sensitive to a number of different lexically related manipulations, many of which seem to be related to word predictability or ease of processing. The N400 has been suggested to reflect degree of integration into context (Kutas and Hillyard, 1980), but also prediction error, which increases with the number of possible word candidates at a given point in a sentence (Rabovsky and McRae, 2014). For instance, N400 amplitudes are smaller for words that have been primed through repetition (Rugg, 1985) or preactivated in the sentence context (Szewczyk and Schriefers, 2018), words that have relatively higher frequency and real words compared to pseudowords (Kutas and Federmeier, 2000; Lau, Phillips, and Poeppel, 2008). Given that the N400 can be modulated by several different factors, it is likely to be the result of activity from several neural generators (Kutas and Federmeier, 2011; Lau et al., 2008).

The fact that the amplitude of the N400 is greater for concrete than abstract words is not straightforwardly explained in terms of ease of processing or predictability. Behavioural experiments have generally shown longer response times and lower accuracy for abstract than concrete words presented in isolation (Paivio, 2010). Since abstract words have less negative N400 amplitudes than concrete words, abstract words might thus be expected to be more easily processed/ more predictable relative to single concrete words, but this has not generally not been reflected in response times. It is not, however, entirely obvious that reaction times and N400 reflect the same kind of semantic processing at the word level. If a word is associated with many semantic features, this could lead to faster activation of a mental image and faster response times as has been found by e.g. Paivio (2010) and Pexman, Holyk, and Monfils (2003), but it could also be the case that for words with many features to be processed and/or integrated in a particular discourse context, semantic processing could be prolonged (Holcomb, Kounios, Anderson, and West, 1999). Indeed, in a study by Barber et al. (2013) using single words where context availability was controlled for, shorter response times were found for abstract words in relation to concrete words. 
The relatively larger N400 amplitude for single concrete nouns in relation to abstract nouns has been explained as the result of greater processing effort involving integration of sensory-motor meaning features into a higher-level representation (Barber et al., 2013; Gullick et al., 2013). The fact that N400 amplitudes are more negative for pseudowords than for real words could be thought to be inconsistent with the explanation that larger N400s are a result of greater semantic feature activation. Intuitively, it could be assumed that pseudowords do not activate semantic features, since they are not associated with any semantic interpretation. However, previous studies have shown that the orthographic/phonological form of pseudowords does, in fact, lead to an activation of similar existing words and thereby associated semantic features (Holcomb, Grainger, and O'Rourke, 2002; Laszlo and Federmeier, 2009, 2011). Orthographic neighbourhood has been shown to modulate the $\mathrm{N} 400$ in the sense that stimuli with relatively many orthographic neighbours show a larger N400 than stimuli with fewer orthographic neighbours. The effect is stronger for pseudowords than real words, presumably because it is difficult to suppress the activation of all the neighbours and resolve the lexical search (Holcomb et al., 2002).

Degree of emotional valence has also been proposed to be a factor driving concrete/abstract word differences (Kousta, Vigliocco, Vinson, Andrews, and Del Campo, 2011). Abstract words can be divided into categories that have high emotional arousal (e.g. love, joy, terror) and low emotional arousal (e.g. thought, relation, variation) which are likely to be processed differently (Blomberg, Roll, Lindgren, Brännström, and Horne, 2015; Dreyer, Frey, Arana, von Saldern, Picht, Vajkoczy, and Pulvermüller, 2015). Most ERP studies comparing abstract and concrete word processing have not systematically varied or attempted to control for emotional content (Gullick et al., 2013; Kounios and Holcomb, 1992, 1994; Nittono et al., 2002; Welcome, Paivio, McRae, and Joanisse, 2011; West and Holcomb, 2000). Among the few exceptions are Kanske and Kotz (2007), who varied concreteness and emotional valence orthogonally, resulting in comparisons of concrete and abstract words with either positive, neutral or negative valence. They found an interaction of concreteness and emotion, with amplitudes in a later time-window (the Late Positive Complex (LPC) being larger for negatively valenced concrete words. Westbury, Shaol, Hollis, Smithson, Briesemeister, Hofmann, and Jacobs (2013) and Westbury, Cribben, and Cummine (2016) observed that effects attributable to imageability correlate highly with other effects related to affect and context. Barber et al. (2013) took emotionality into account by matching their abstract and concrete stimuli along the dimension of emotional valence. As noted above, they found a behavioural "abstractness effect", i.e. shorter response times for abstract words, combined with the expected greater N400 negativity for concrete words. In the present study, we aim to shed light on 
the potential influence of emotional arousal in modulating the N400 for different word categories.

In sum, the above studies all offer accounts for N400 patterning in some of the situations where it arises, but there does not seem to be a model accounting for all of them.

\section{Concrete words, imageability, and semantic specificity}

In linguistic models of the lexicon, concrete words have been assumed to be characterized by different hierarchical levels of semantic structure. Thus, the difference in meaning between words like squirrel vs. animal can be related to their level of semantic categorization (Miller and Fellbaum, 1991; Cruse, 1986) where words on lower, subordinate levels like squirrel (here, called 'specific' nouns) are characterized by relatively many defining semantic features, whereas words on higher, superordinate levels like animal (here called 'general' nouns) are associated with fewer defining features. This difference can also be seen as a difference in abstraction (Blomberg et al., 2015; Dove, 2016), where words on higher lexical semantic levels are relatively more abstract than words on lower levels of the semantic hierarchy. Although the specific-general relation has a central role in models of lexical semantics and cognitive organisation (Rosch, Mervis, Gray, Johnson, and Boyes-Braem, 1976), it has rarely been the focus of neurolinguistic studies or studied in relation to the parameter of concreteness (Dove, 2016). In one early study (Kounios and Holcomb, 1992), relatively specific nouns (e.g. dog) produced more negative amplitudes than more general nouns (e.g. animal). This was seen with a stimulus set where concreteness ratings were higher for the more general nouns, indicating that the process behind the difference was not related to concreteness. In the present study, concreteness will be related to the rating-based parameter of imageability (how easily a word gives rise to a sensory experience) (Gilhooly and Logie, 1980; Paivio, Yuille, and Madigan, 1968). ${ }^{1}$

As noted above, a central assumption of lexical semantics is that subordinate concepts in a semantic domain share the semantic features which define their general/superordinate concept. For example, horse has all the defining features of animal plus features that distinguish horses from other kinds of animals (Miller and Fellbaum, 1991; Rosch et al., 1976). Furthermore, Rosch and Lloyd (1978) suggested that the 'basic' level of semantic categorisation is the most general level

1. Although not identical, imageability is highly correlated with another cognitive parameter, 'concreteness' (Westbury et al., 2013). Imageability and concreteness ratings are often used interchangeably to measure concreteness (Nittono, et al., 2002; Sabsevitz, Medler, Seidenberg, and Binder, 2005; Westbury and Moroschan, 2009). 
where a mental image corresponding to the class as a whole can be formed. This leads to the prediction that superordinate/general concrete nouns like vegetable would be associated with a lower rating for imageability than a specific noun like carrot (which is not true in this particular case: vegetable $=598$, carrot $=577$ (Coltheart, 1981)). In stimulus sets in previous studies comparing words at specific and general levels, specific nouns have had higher imageability ratings than general nouns (Blomberg et al., 2015), as well as lower concreteness ratings (Kounios and Holcomb, 1992). Thus, the question remains as to whether the hierarchical structure assumed to hold for specific and general nouns is governed by factors other than the cognitive psychological parameter of imageability.

If there were differences in the ERPs elicited by general and specific nouns, it would be interesting to see if such effects varied with degrees of imageability associated with the general and specific terms or if they would differ, independently of imageability, perhaps due to other properties of the general and specific words. If they occurred in a more restricted set of discourse contexts, specific nouns would not be expected to be associated with as many other words as general nouns. Interestingly, general nouns are also important as anaphoric expressions in discourse, and commonly used to refer back to more specific concepts (Ariel, 1990).

\section{Semantic neighbourhood}

Even when presented as single test items, it has become increasingly clear that words activate other words in addition to their own intrinsic lexical content. According to theoretical accounts proposed by Crutch, Connell, and Warrington (2009) and Crutch and Warrington $(2005,2010)$, the meanings of abstract words are primarily organised on the basis of associative relations with other words, whereas concrete words are organised based on taxonomic similarity. Empirical support for this idea has been found by Recchia and Jones (2012) in a study on English where number of semantic neighbours was seen to be a significant predictor of lexical decision time variance for abstract words, whereas the number of semantic properties was a significant predictor of lexical decision time variance for concrete words. ${ }^{2}$ In a further study on English using a number of lexical measures including orthographic neighbourhood size and number of lexical associates, Laszlo and Federmeier (2014) found that the number of lexical associates

2. Recchia and Jones (2012) calculated semantic neighbourhood size using 'pointwise mutual information', a measure of association contrasting the actual probability of observing two items together in a corpus, with the probability of having observed them together if they had been independently distributed. 
(responses from free-association tasks) ${ }^{3}$ was a reliable predictor for the N400 amplitude in their test stimuli which included words, pseudowords, acronyms and illegal strings.

\section{The present study}

\section{Aims}

The present study aimed to investigate how semantic neighbourhood as well as affective meaning and orthographic neighbourhood contribute to modulating the N400 in a lexical decision experiment. On the concrete side of the spectrum, hierarchically related SPECIFIC (e.g. hammer) and GENERAL (e.g. tool) noun categories were distinguished. The abstract nouns were further divided into the two categories, EMOTIONAL (high emotional arousal, e.g. anger) and ABSTRACT (low emotional arousal, e.g. relation). The four noun categories were compared with phonotactically legal PSEUDOWORDS.

We used a method related to that used by Shaoul and Westbury (2006) and Recchia and Jones (2012) to calculate discourse related semantic associate measures for the testwords and correlate them with N400 amplitudes. If the number of semantic associates correlates with differences in word concreteness and N400 amplitudes, this could potentially shed light on differences based on concreteness or specificity. Highly concrete / specific words could be expected to have a more restricted number of semantic associates than other word categories. Furthermore, the greater negativity associated with pseudowords could be accounted for by the fact that they do not occur naturally in discourse. As in previous studies (Holcomb et al., 2002; Laszlo and Federmeier, 2009, 2011), we also calculated the orthographic neighbourhood for test word categories to see if and how this measure interacted with results for the N400. In addition, we tested to what extent the emotional arousal associated with the different test word categories modulated the N400. As in the above-mentioned studies, we used an isolated word paradigm for studying $\mathrm{N} 400$ effects in a response time experiment in order to avoid preactivation of semantic information that would be available in a sentence paradigm and that would lead to a reduction of the N400 effects (see also Kutas and Federmeier, 2011).

3. Retrieved from the South Florida Norms (http://w3.usf.edu/FreeAssociation/) 


\section{Predictions}

In line with results from previous studies, PSEUDOwORDs were expected to yield more negative N400 amplitudes than all of the real word categories. Also following results of earlier investigations, larger N400 amplitudes were expected for the concrete subcategories SPECIFIC and GENERAL nouns than for the abstract categories EMOTIONAL and ABSTRACT nouns.

It was further assumed that if there were larger N400 effects for SPECIFIC than GENERAL nouns in an imageability-matched subset of the testwords, this would provide support for the idea that lexical semantic specificity contributes to the modulation of the N400, independently of degree of imageability.

The relationship between testword categories and the number of contextually related semantic associates led to further predictions. Whereas PSEUDOwORDS do not naturally co-occur in discourse with other words, concrete words were expected to have relatively few associates in relation to abstract words. Furthermore, the more superordinate category of GENERAL nouns like animal, due to their tendency to be used as anaphoric expressions in discourse (Ariel, 1990), were expected to have relatively more semantic associates in relation to SPECIFIC nouns like elephant and thus were predicted to yield smaller N400 amplitudes than SPECIFIC nouns.

The abstract categories in the present study both had higher values for emotional arousal than the concrete (SPECIFIC and GENERAL) categories, but in addition, the ЕмотіONAL nouns had significantly higher arousal values than the ABSTRACT nouns. This relationship thus provided the opportunity to see whether there was variation in the N400 predicted by imageability or emotional arousal or whether EмотіONAL nouns are processed in the same way as other abstract nouns. One possible outcome might be a concreteness effect, seen as a greater N400 amplitude for the EMOTIONAL than for the ABSTRACT nouns, which could be expected based on their higher imageability as compared to the ABSTRACT nouns. However, another possibility might be that, in contrast to the other word categories, EMOTIONAL nouns have affective meaning components assumed to stem from processing in limbic regions of the brain (Pulvermüller, 2013; Kousta et al., 2011). This embodied meaning might interact with other parameters influencing the N400, resulting in a lower amplitude for EMOTIONAL nouns in relation to ABSTRACT nouns.

Response times (RT) for lexicality judgements were expected to vary from short to long in the order SPECIFIC - GENERAL - EMOTIONAL - ABSTRACT, based on previously found concreteness effects. PSEUDOWORDS were expected to have the longest RTs. 


\section{Method}

\section{Participants}

35 participants ( 17 female), aged $20-37$ years, took part in the study. All participants were right-handed as assessed by a modified version of the Edinburgh handedness questionnaire (Oldfield 1971) and all reported normal or correctedto-normal vision and no history of neurological or psychiatric disease. All participants gave their informed consent to partake in the investigation prior to the experiment. The study was conducted in accordance with the Helsinki Declaration. Participants received an hourly wage.

\section{Stimuli}

The stimuli consisted of 160 visually presented Swedish words (see Appendix A) and 160 pseudowords (see Appendix B). There were 40 words in each word category (SPECIFIC, GENERAL, EMOTIONAL, ABSTRACT). ${ }^{4}$ The SPECIFIC words were selected from semantically subordinate levels in relation to the corresponding GENERAL words, i.e. ekorre 'squirrel' is on a lexical semantic subordinate level in relation to djur 'animal. The words were all nouns with 1-4 syllables. The stimuli belonging to the different categories were matched for number of syllables and written frequencies from the Stockholm Umeå Corpus (Ejerhed, Källgren, Wennstedt, and Åström, 1992). One-way ANOVAs revealed no significant differences between the word categories as regards number of syllables ( $F(3$, $156)=0.113, p=0.952)$ or written frequency $(F(3,156)=0.007, p=0.999))$. Pseudowords were phonotactically legal and had the same number of syllables as the real words. Kounios and Holcomb (1994) as well as Barber et al. (2013) used pseudowords created from the real concrete and abstract words used in the same experiment, e.g. teble and jastice (Kounios and Holcomb, 1994). In order to avoid obvious associations to real words, such a matching was not used in the present study (see also Kanske and Kotz, 2007).

When available, imageability ratings for English translations of the Swedish test words were obtained from the MRC psycholinguistic database (Coltheart, 1981). For items where imageability ratings were not present in the MRC database, Swedish imageability ratings were taken from two data collections carried out prior to the present study (Blomberg and Öberg, 2015; Blomberg, 2016). In order to control for possible between-language differences in word ratings, Swedish

4. One of the AвSTRACт words (fakta 'fact') was inadvertently presented two times in the experiment. 
ratings of imageability were then used for the same proportion of words in each word category (9/40). A one-way ANOVA showed an effect of word category on imageability $(F(3,156)=96.532, p<0.001)$ and follow-up Tukey tests revealed significant differences in imageability for each word category $(p$ values $<0.05)$, going from high to low in the direction SPECIFIC > GENERAL > EMOTIONAL > ABSTRACT. ${ }^{5}$

Emotional arousal ratings were taken from three previous Swedish data collections (Blomberg et al., 2015; Blomberg and Öberg, 2015; Blomberg, 2016). A one-way ANOVA indicated significant differences in emotional arousal between word categories $(F(3,155)=157.921, p<0.001)$. Post hoc Tukey tests revealed significant differences in emotional arousal between all categories ( $p$ values $<0.001$ ), except for GENERAL and SPECIFIC words $(p=0.805)$. The emotional arousal of test words in the EMOTIONAL category was the highest, followed by those in the ABSTRACT category. GENERAL and SPECIFIC words were close to equally low in emotional arousal.

A subset of the GENERAL and SPECIFIC words (see Appendix C) was analysed separately in order to see whether there would be differences in ERP amplitudes for these words at different levels of semantic specificity, independently of their ratings for imageability. Not only was there no significant difference in imageability $^{6}(F(1,26)=0.258, p=0.616)$ but also their values for emotional arousal $(F(1$, $26)=0.318, p=0.577)$, written frequency $(F(1,26)=0.049, p=0.826)$, and number of syllables $(F(1,26)=1.051, p=0.315)$ did not show any statistically significant difference.

\section{Procedure}

A lexical decision (LD) experiment with visually presented stimuli was conducted using E-Prime 2.0.10 (2012). Participants were seated in front of a Dell EI72FP 17' computer screen at a distance of $100-110 \mathrm{~cm}$. Written instructions were presented on the screen prior to the experiment, followed by 24 practice trials with words/

5. In order to confirm imageability differences between word classes, an imageability rating task was administered after the LD experiment where the same test persons rated test words on a scale of $1-5$. The imageability ratings were seen to decrease in the direction SPECIFIC $(M=4.66, S D=0.482)>\operatorname{GENERAL}(M=3.86, S D=0.733)>$ EMOTIONAL $(M=3.09, S D=0.887)>$ ABSTRACT $(M=2.37, S D=0.808)$. A repeated-measures ANOVA showed a significant main effect of word category $\left(F(3,102)=108.811, p<0.001, \eta_{p}^{2}=0.762\right)$. Post hoc comparisons with Bonferroni corrected tests showed that there were significant differences between all four word categories (all p:s < 0.001 ).

6. There was even a non-significant difference in the opposite direction with the general stimuli having slightly higher imageability ratings. 
pseudowords not appearing in the real experiment. There was an opportunity to ask questions after the practice trials. Words were presented in a white 32p Arial font on a black background. Each trial began with a fixation cross displayed for $500 \mathrm{~ms}$, followed by a word/pseudoword displayed for $1500 \mathrm{~ms}$. Subjects were instructed to judge the test stimuli's lexicality and respond as quickly as possible, but at the same time to be as careful as possible in making their response. No response feedback was given. Following the $1500 \mathrm{~ms}$ word presentation, the next trial began regardless of whether a response was given or not. "Yes/No" responses were made to the question "Is it a real word?" with the left and right index fingers using a PST Serial Response Box. In order to avoid effects of hand dominance, the use of right or left index finger for Yes/No was counterbalanced across participants.

\section{EEG recordings}

EEG was recorded with 32 electrodes mounted on an elastic cap (Easycap), using a SynAmps 2 amplifier and Curry7 software. Electrodes placed at the outer canthi of the eyes and above and below the left eye recorded the electrooculogram. Mi was used as the online reference, re-referenced offline to the average of the mastoids. A frontal cap mounted electrode was used as ground. The scalp electrodes were positioned according to the 10/20 system (Jasper, 1958) as shown in Figure 1. The sampling rate was $500 \mathrm{~Hz}$ and an online bandpass filter (Butterworth) was applied. Electrode impedances were kept below $5 \mathrm{k} \Omega$.

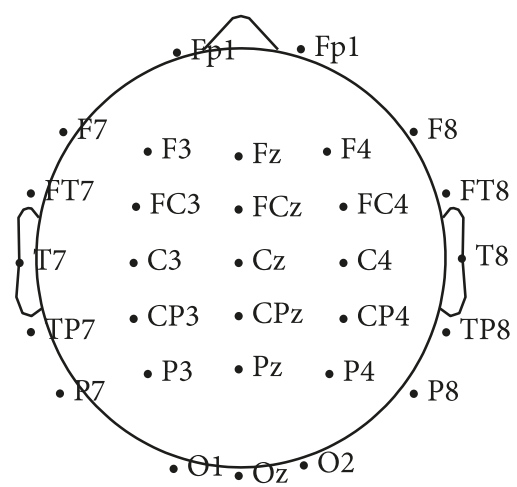

Figure 1. Positioning of the scalp electrodes 


\section{Data analysis}

All statistical analysis of behavioural results was made by means of repeatedmeasures ANOVAs using SPSS. The EEG data were analyzed offline using EEGLAB (Delorme and Makeig, 2004). An offline bandpass filter with the cutoff frequencies $30 \mathrm{~Hz}$ lowpass and $0.05 \mathrm{~Hz}$ highpass was applied. The data were then segmented into $1000 \mathrm{~ms}$ epochs following word onset. A time window of $200 \mathrm{~ms}$ before word onset was used for baseline correction. Independent components analysis (ICA) (Jung, Makeig, Humphries, Lee, McKeown, Iragui, and Sejnowski, 2000) was used to compensate for ocular artifacts. Trials with an amplitude exceeding $\pm 100 \mu \mathrm{V}$ after ICA were rejected. One participant was excluded from the analysis due to excessively noisy data ( $>40 \%$ rejected). Statistical analysis of EEG data was performed using SPSS and EEGLAB. Mean amplitudes per participant, time window, and condition were compared using repeated-measures ANOVAs. Five levels of word category $($ PSEU $=$ PSEUDOWORD $/$ SPEC $=$ SPECIFIC $/$ GEN $=$ GENERAL $/$ EMO = EMOTIONAL $/$ ABS = ABSTRACT) and six ROI:S (LA= LEFT ANTERIOR: F3, FC3 / MA= MID ANTERIOR: FZ, FCZ / RA=RIGHT ANTERIOR: F4, FC4 / LP = LEFT POSTERIOR: CP3, P3 / MP = MID POSTERIOR: CPZ, PZ / RP = RIGHT POSTERIOR: CP4, P4) were included. Pairwise posthoc comparisons were Bonferronicorrected. Furthermore, in order to be able to see whether possible differences between SPECIFIC and GENERAL words could be assumed to be driven more by lexical semantic specificity than imageability, a subset of the SPECIFIC and GENERAL stimuli matched for imageability ( 14 of each category) were analysed. In the cases when Mauchly's test showed violations of the assumption of sphericity, Greenhouse-Geisser correction was applied. In such cases, corrected p-values and uncorrected degrees of freedom are reported.

\section{Analysis of semantic neighbourhood: Semantic associates (SA)}

As noted above, different methods have been used to determine a measure of semantic neighbourhood, depending to a certain extent on what lexical resources are available for the language studied. Laszlo and Federmeier (2014) used a database of word associations for English to determine the number of lexical associates per word, whereas Recchia and Jones (2012) used a probability-based measure of association. As our target language is Swedish, for which there is no word association database available, we determined the number of semantic neighbours in another way, by using word vectors.

Word vectors constitute a way to numerically represent the meanings of words in context. They rely on a specific view of word meaning, i.e. that meaning comes from usage, or in other words, that the meaning of a word comes from the way we use the word in everyday life. The underlying idea comes from the distributional 
hypothesis which states that there is a correlation between distributional similarity and meaning similarity (Sahlgren, 2008).

The idea is fairly old (Harris, 1954; Firth, 1957) and the first practical models such as HAL (Lund and Burgess, 1996) and COALS (Rohde, Gonnerman, and Plaut, 2006) were count-based in that co-occurrences within a certain word length window were accumulated to form a vector representation. Collobert and Weston (2008) introduced a neural network architecture where the representation of a target term instead is fitted to predict the representations of its lexical context. Mikolov, Chen, Corrado, and Dean (2013) created word2vec, a toolkit that allows the seamless training and use of pre-trained vectors. Count-based distributional semantic methods and predictive neural network models have been shown to achieve similar results (Levy, Goldberg, and Dagan, 2015; Zuccon, Koopman, Bruza, and Azzopardi, 2015).

The word vectors used here are effectively realised by a neural network that is trained with text in a way that words can predict which other words it will cooccur with. Furthermore, the network can calculate a probability that two words are associated. We used fastText (Bojanowski, Grave, Joulin, and Mikolov, 2017), an efficient and easily-accessible implementation of word vectors. An advantage of fastText compared to other popular implementations (such as Word2Vec and Glove) is that it already has a model for Swedish trained on millions of words taken from the Swedish version of the free online encyclopedia Wikipedia and data from the common crawl project.

As an example, when fastText is run to calculate the ten words most similar to the query word ekorre 'squirrel', the results found in Table 1 are obtained:

Table 1. A ranked list of contextually related semantic associates (SA) for the Swedish word ekorre 'squirrel', as well as the strengths of these SA

\begin{tabular}{llc}
\hline Rank & SA & SA strength \\
\hline 1 & ekorren 'squirrel (def.)' & 0.706340 \\
2 & ekorrar 'squirrel (pl.)' & 0.690712 \\
3 & flygekorre 'flying squirrel' & 0.679126 \\
4 & jordekorre 'ground squirrel' & 0.643060 \\
5 & spetsekorre 'tree shrew' & 0.618023 \\
6 & ekorrarna 'squirrel (pl. def.)' & 0.613329 \\
7 & räv'fox' & 0.603779 \\
8 & känguru 'kangaroo' & 0.593162 \\
9 & Ekorre 'Squirrel' & 0.592093 \\
10 & sork 'field mouse' & 0.576753 \\
\hline
\end{tabular}


Thus, for a given query word, a ranked list with associated words can be obtained, as well as the strengths of their semantic associates (SA). By setting a threshold, the number of words that are semantically close enough to the query word can be determined. It is also possible to extract the top $\mathrm{N}$ words for a query word and then calculate the mean association strength. For the present study, we chose to count the number of SAs over a threshold of 0.3. A ceiling for number of SAs was set to 10000 words.

Analysis of orthographic neighbourhood

Orthographic neighbours $(\mathrm{ON})$ can be found for a given word by searching through a lexical database and calculating a measure of 'neighbourhoodness' between the target word and the words in the database. In this way the number of ONs a word has can be determined. For the present study, we used the publically available NST database (Andersen, 2011) and the Levenshtein distance (LD) as a measure, and extracted all words with $\mathrm{LD}=1$ for each target word.

Although the vocabulary of any language is, in principle, infinite, the number of words included in a lexical database must be finite. Thus, the actual choice of words may be somewhat arbitrary and the lexicon may contain words with very low usage, potentially introducing some undesired noise in the lexical competition scores. In order to somewhat mitigate this arbitrariness, we applied a frequency threshold to the lexicon. We matched the lexical database with a word frequency list based on the Swedish PAROLE corpus, and in the final version of the database, only words that had a PAROLE frequency of 2 or greater were included. In this way, we weighed in actual word usage.

As an example, the word tavla 'painting' has an ON score of 5, and has the following neighbours with $\mathrm{LD}=1$ : avla 'breed', kavla 'roll', tala 'speak', tävla 'compete' and tavlan 'painting (def.)'

\section{Results}

Behavioural results: Lexical decision (LD)

Response accuracy was high (98.1\% correct responses) in the LD task and was highest for SPECIFIC and EMOTIONAL nouns. RTs varied between word categories (Figure 2), being longest for PSEUDOwORDS $(M=705 \mathrm{~ms}, S D=82)$, and shortest for the word categories with the highest imageability (SPECIFIC) $(M=619 \mathrm{~ms}, S D=64)$ and the highest emotional arousal (EMOTIONAL) $(M=625 \mathrm{~ms}, S D=63)$. RT's were longer for General $(M=635 \mathrm{~ms}, S D=63)$ and ABStraCt $(M=638 \mathrm{~ms}, S D=68)$ 
nouns. A repeated-measures ANOVA revealed a significant main effect of word category, $\left(F(3,99)=6.787, p<0.001, \eta_{p}^{2}=0.171\right.$. Bonferroni corrected follow-up tests revealed that this effect was due to significant differences between SPECIFIC and GENERAL nouns $(p=0.012)$, SPECIFIC and ABSTRACT nouns $(p=0.001)$, and ABSTRACT and EMOTIONAL nouns $(p=0.021)$.

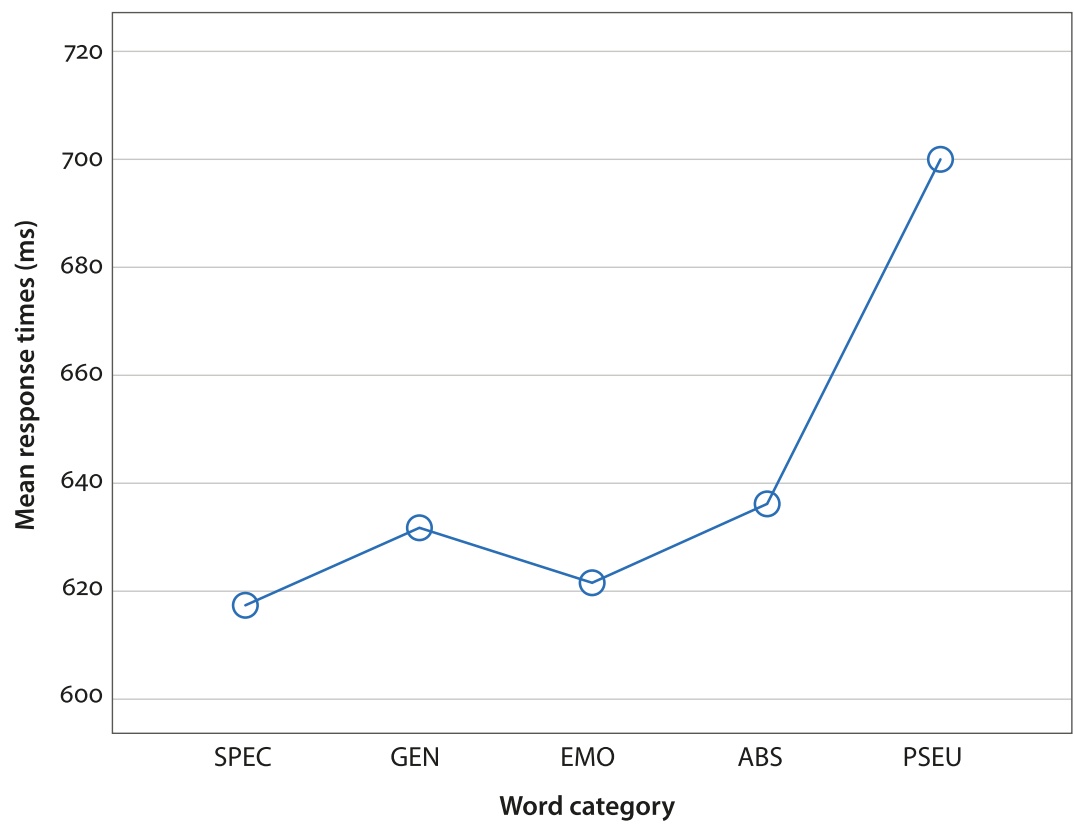

Figure 2. Mean response times for the four word categories (SPEC, GEN, ABS, EMO) and pseudowords (PSEU)

\section{Regression with continuous measures}

In a linear regression analysis, the number of semantic associates (SA), $p=0.018$, and number of orthographic neighbours $(\mathrm{ON}), p=0.016$, both decreased response times, as seen in formula (1), $R^{2}=0.074, F(2,159)=6.26, p=0.002$.

(1) $R T=669-0.18 S A-0.19 O N m s$

In a linear regression analysis including emotional arousal (EA), carried out on the subset of words that had an EA rating, $R^{2}=0.075, F(3,101)=2.74, p=0.047$, the only significant predictor of RT was $\mathrm{ON}, p=0.027$. Neither SA, $p=0.223$, nor $\mathrm{EA}, p=0.268$, were significant. 
ERP results

N400 (300-50o ms time-window)

Results from the LD task were consistent with the overall hypothesis that N400 amplitudes would be the largest for PSEUDOWORDS, smaller for concrete (SPECIFIC and GENERAL) nouns and smallest for abstract (EMOTIONAL and ABSTRACT) nouns (Figure 3 and Table 2). A repeated-measures ANOVA revealed a significant main effect of word category $\left(F(4,132)=50.636, p<0.001, \eta^{2}{ }_{p}=0.605\right)$ as well as a word category $x$ ROI interaction $\left(F(20,660)=3.710, p=0.001, \eta_{p}^{2}=0.101\right)$. Bonferronicorrected post-hoc tests showed that PSEUDOWORDs differed significantly from all other word categories $(p<0.01)$. SPECIFIC nouns also differed significantly from all other categories $(p<0.01)$. GENERAL nouns differed significantly from all categories $(p<0.01)$ except ABSTRACT nouns $(p<0.095)$. Finally, EMOTIONAL nouns differed significantly from all categories except ABSTRACT nouns, where there was a trend towards a difference $(p=0.061)$.

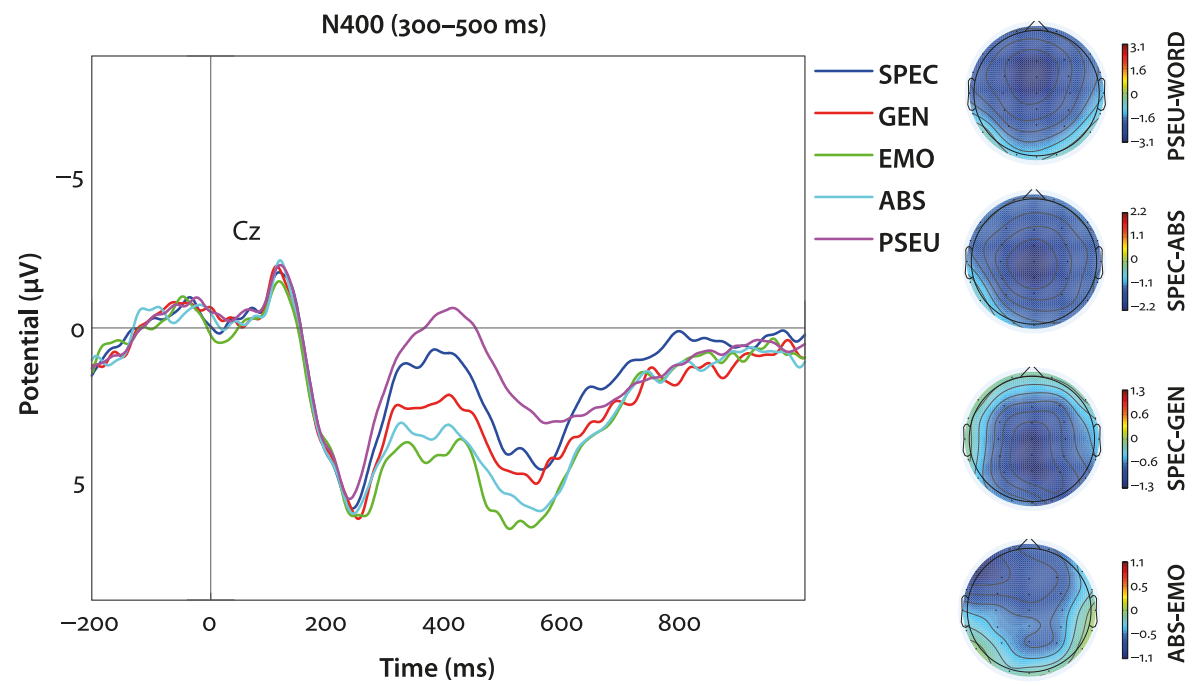

Figure 3. Grand average ERP waveforms, including all word types (SPEC, GEN, EMO, ABS, PSEU), together with topographic maps showing the scalp distribution of the significant effects for the N400 comparisons. The N400 has a central distribution except for the ABSEMO comparison, which has a left frontal distribution 
Table 2. Average ERP amplitudes $(\mu \mathrm{V})$ in the N400 time window (300-500 ms)

\begin{tabular}{lcccccc}
\hline & \multicolumn{6}{c}{ Electrode site } \\
\cline { 2 - 7 } & LA & MA & RA & LP & MP & RP \\
\hline PSEU & 0.47 & 0.17 & 0.70 & 1.43 & 2.23 & 2.14 \\
SPEC & 2.03 & 1.89 & 2.01 & 2.48 & 3.24 & 2.86 \\
GEN & 2.79 & 2.85 & 2.82 & 3.42 & 4.48 & 3.87 \\
ABS & 3.62 & 3.76 & 3.63 & 4.03 & 5.21 & 4.54 \\
EMO & 4.48 & 4.57 & 4.34 & 4.46 & 5.77 & 5.06 \\
\hline
\end{tabular}

\section{Imageability-matched SPECIFIC/GENERAL words}

Following visual inspection of the ERP curves (Figure 4), the subset of SPECIFIC and GENERAL stimuli matched for imageability was compared during a smaller time-window within the N400 range (375-425 ms). Amplitudes were seen to be significantly more negative for SPECIFIC than GENERAL nouns, as shown by a repeated-measures ANOVA $\left(F(1,33)=5.236, p=0.029, \eta_{p}^{2}=0.137\right)$, with no significant word category x ROI interaction $\left(F(5,165)=0.576, p=0.719, \eta^{2}{ }_{p}=0.017\right)$.

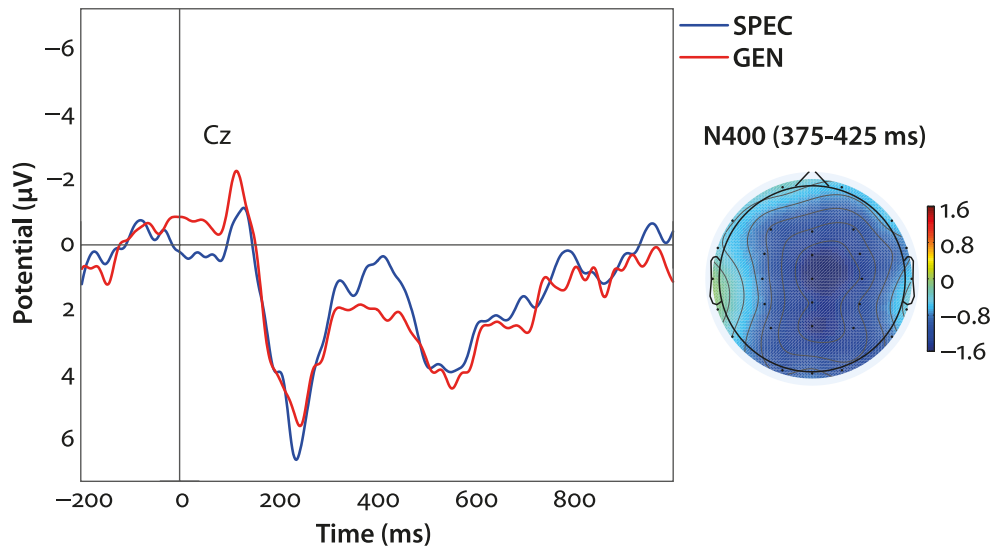

Figure 4. Grand average ERP waveforms for SPEC and GEN words matched for imageability, together with topographic map showing the scalp distribution for the N400 SPEC - GEN comparison

\section{Regression with continuous measures}

A linear regression analysis showed that the number of semantic associates (SA) attenuated the N400, $p=0.001$, whereas the number of orthographic neighbours $(\mathrm{ON})$ increased the $\mathrm{N} 400, p=0.004$, as seen in formula $(2), R^{2}=0.106, F(2$, 157) $=9.31, p<0.001$. 


\section{(2) $\operatorname{ERP}_{N 400}=1.9+0.26 \mathrm{SA}-0.22 \mathrm{ON} \mu \mathrm{V}$}

A regression analysis including emotional arousal (EA) was also performed for all words that had a measure for EA, $N=104$. The $\mathrm{N} 400$ decreased with $\mathrm{EA}, p<0.001$, and SA, $p=0.005$, and increased with $\mathrm{ON}, p<0.001$, as seen in formula (3), $R^{2}$ $=0.287, F(3,101)=13.55, p<0.001$.

(3) $E R P_{N 400}=0.64+0.35 E A+0.24 S A-0.31 O N \mu V$

\section{Discussion}

N400 and RT differences between the test word categories

N400 amplitudes were greatest for PSEUDOWORDs, followed by the concrete subcategories SPECIFIC and GENERAL nouns, and smallest for the abstract subcategories abStract and emotional nouns (see Figure 3). By using both linguistic and cognitive psychological parameters, including emotional arousal, orthographic neighbourhood, and semantic associates, the present study showed how these factors modulate the N400. This variation in N400 amplitudes for isolated words highlights the fact that the N400 is affected by a number of different parameters. Greater activation of semantic features could explain the larger N400 amplitudes for concrete than for abstract words (see Pexman et al., 2003; Grondin, Lupker, and McRae, 2009), and even the large amplitude for pseudowords assuming that phonotactically legal pseudowords activate large numbers of semantic features (Laszlo and Federmeier, 2009). The fact that pseudowords do not have any real word semantic associates, however, can account for why the N400 is greatest for them, since a discourse context cannot be identified and associated with them. The processing of words is also affected by their orthographic form, and results here show that the number of orthographic neighbours correlates with an increase in the amplitude of the N400. This result is in agreement with that in Holcomb et al. (2002) and Laszlo and Federmeier (2011) suggesting that orthographic information is processed in parallel with semantic information during the N400 time window.

Semantic associates as predictors of N400 in real words

The comparison of the concrete subcategories SPECIFIC and GENERAL nouns yielded significantly more negative, centrally distributed N400's for SPECIFIC words. This could be interpreted as an imageability effect for the sPECIFICGENERAL comparison, being evident even though the SPECIFIC-GENERAL distinction was based on more subtle imageability differences than those of the abstract 
and concrete words compared in previous studies. However, a subset of SPECIFIC and GENERAL stimuli matched for imageability still yielded significantly greater negativities for SPECIFIC nouns in a more limited time-window (375-475 ms). This suggests that something other than imageability contributes to the effect, possibly related to the hierarchical lexical semantic relationship between SPECIFIC and GENERAL nouns. The analysis of SA shows that SPECIFIC nouns have significantly fewer SAs than GENERAL nouns. Thus, nouns at a lower taxonomic level have smaller semantic neighbourhoods than other nouns. The fact that the N400 amplitudes differed significantly for GENERAL and SPECIFIC nouns, but not for GENERAL and ABSTRACT nouns, indicates that although GENERAL nouns are often seen as concrete and are frequently rated as highly imageable, their processing is nevertheless more like ABSTRACT than SPECIFIC words since they both have relatively more contextually related SAs in relation to SPECIFIC words.

\section{Role of affective meaning in modulating the N400}

EMOTIONAL nouns had higher imageability values than ABSTRACT nouns, but nevertheless showed a trend towards lower N400 amplitudes than ABSTRACT nouns over left anterior electrodes. Since it is possible that affective semantic content makes N400 amplitudes smaller due to influence of other neurophysiological effects from processing emotional content, further studies would be necessary in order to draw strong conclusions about differences in the processing of EMOTIONAL and ABSTRACT nouns. In the present study, inclusion of emotional arousal in the regression model for predicting N400 indicates that is a parameter that contributes to a lowering of the N400.

\section{The N400 for abstract words and language processing}

The neurophysiological results showing a more left anterior distribution of the N400 for abstract compared to emotional words, together with the semantic analysis showing a greater number of SAs for abstract words (both EMOTIONAL and ABSTRACT) than concrete nouns support previous findings from studies on word processing in persons with Broca's aphasia. For example, in relation to control subjects, Roll, Mårtensson, Sikström, Apt., Arnling-Bååth, and Horne (2012) found a relatively low degree of use of abstract words in the speech of persons with damage to Broca's area, a cortical area known to be highly involved in coordinating integration of information in sentence and discourse processing, and lower semantic similarity in their associations to abstract words. Mårtensson, Roll, Apt, and Horne (2011) and Mårtensson, Roll, Lindgren, Apt, and Horne (2014) found 
a relatively greater use of abstract words by a patient with an intact Broca's area but with damage to occipital areas where visually related semantic features are processed. These findings for abstract words provide evidence for assumptions in cognitive psychological approaches to word meaning, such as Paivio's 'dual coding theory', which posits that abstract words are more exclusively 'languagedependent', whereas concrete words are associated with additional sensory information (Paivio, 1990, 2010) or the approach of Crutch et al. (2009) and Crutch and Warrington $(2005,2010)$ who assume that concrete words tend to be organised on the basis of taxonomic similarity, whereas abstract words are primarily organised on the basis of associative relations with other words (semantic neighbours).

\section{Behavioural results}

RTs did not show a consistent pattern in relation to N400 amplitude values for the different test word categories. For real words, RT's were the fastest for SPECIFIC and EMOTIONAL nouns, suggesting that semantically subordinate concrete nouns associated with relatively many sensory features (high imageability), as well as nouns associated with affective content (high emotional arousal) facilitated lexicality decisions. Interestingly, there was a significant difference between the RTs for the subcategories within the abstract test words (EMOTIONAL and ABSTRACT nouns), as well as the subcategories within the concrete test words words (sPECIFIC and GENERAL nouns) which suggests a relatively similar influence of sensory and affective content on the speed of processing SPECIFIC and EMOTIONAL words. This finding supports embodied theories of the representation of abstract words (see Kousta et al., 2011) which assume a high degree of integration between affective and sensory motor parameters when processing word meaning. Interestingly, in a dichotic listening study, Blomberg et al. (2015) found that SPECIFIC words had the fastest RTs when presented to the right ear (left hemisphere), while EMOTIONAL words had the fastest RTs when presented to the left ear (right hemisphere). Thus, although SPECIFIC and EMOTIONAL words are processed in different ways, their embodied meaning features enhance speed of lexical decision. The facilitatory effect of emotional content has also been observed by Siakaluk, Newcombe, Duffels, Li, Sidhu, Yap., and Pexman (2016). In the regression analyses, phonological neighbourhood was the most stable predictor of RTs. Results showed that the larger the phonological neighbourhood, the faster participants could make a decision about a word's lexicality. 


\section{Conclusion}

The results of the present study have implications for the interpretation of N400 effects for words out of context. They provide further evidence for the interpretation of the $\mathrm{N} 400$ as a reflection of a stage in the multimodal processing of a stimulus when meaning is emerging (Kutas and Federmeier, 2011). Our findings show that, in addition to being correlated with the cognitive parameter emotional arousal, single words' N400 amplitudes, like words in context, are to a significant degree modulated by their latently associated semantic and orthographic neighbourhoods. The N400 amplitude distribution pattern found in the present study for the different test word categories (PSEUDOWORD $>$ SPECIFIC $>$ GENERAL $>$ ABSTRACT $>$ EMOTIONAL) can be accounted for by assuming that the N400 evoked by a single word out of context is affected by a combination of the number of contextually related semantic associates, orthographic neighbours, as well as the degree of emotional arousal it has. In short, the present study has shown that the amplitude of the N400 is lower the more semantic associates a word has and the more emotional content it has. Moreover, the N400 increases the more orthographic neighbours it has. The results of the study contribute to the literature on the theoretical modelling and processing of word semantics. In particular, they provide evidence for the hierarchical organisation of concrete words assumed in lexical semantics and for the contribution of affective content in facilitating the processing of word meaning.

\section{Funding}

The present study was supported by grants 421-2004-8918, 2013-2003 (Swe-Clarin) and 3492007-8695 from the Swedish Research Council.

\section{Acknowledgements}

The authors gratefully acknowledge Lund University Humanities Lab for providing research facilities. We also wish to thank Anna Hed for help with data collection.

\section{References}

Andersen, G. (2011). Leksikalsk database for svensk. Oslo: Technical report, Nasjonalbiblioteket. Ariel, M. (1990). Accessing noun-phrase antecedents. London: Routledge.

Barber, H.A., Otten, L. J., Kousta, S.-T., \& Vigliocco, G. (2013). Concreteness in word processing: ERP and behavioral effects in a lexical decision task. Brain and Language 125, 47-53. https://doi.org/10.1016/j.bandl.2013.01.005 
Blomberg, F. (2016). Concreteness, specificity, and emotional content in Swedish nouns. Neurocognitive studies of word meaning. (Doctoral dissertation). Retrieved from: https://lup.lub.lu.se/search/publication/4a492bdf-2d91-4955-a820-1143d470d624

Blomberg, F., \& Öberg, C. (2015). Swedish and English word ratings of imageability, familiarity and age of acquisition are highly correlated. Nordic Journal of Linguistics 38, 351-364. https://doi.org/10.1017/So332586515000220

Blomberg, F., Roll, M., Lindgren, M., Brännström, K. J., \& Horne, M. (2015). Emotional arousal and lexical specificity modulate response times differently depending on ear of presentation in a dichotic listening task. The Mental Lexicon 10, 221-246. https://doi.org/10.1075/ml.10.2.03blo

Bojanowski, P., Grave, E., Joulin, A. \& Mikolov, T. (2017). Enriching word vectors with subword information. Transactions of the Association for Computational Linguistics 5, 135-146. https://doi.org/10.1162/tacl_a_00051

Collobert, R. \& Weston, J. (2008). A unified architecture for natural language processing: Deep neural networks with multitask learning. Proceedings of the 25th International Conference on Machine Learning. ACM, 160-167.

Coltheart, M. (1981). The MRC psycholinguistic database. The Quarterly Journal of Experimental Psychology Section A 33, 497-505. https://doi.org/10.1080/14640748108400805

Cruse, A. (1986). Lexical semantics. Cambridge: Cambridge University Press.

Crutch, S. J., \& Warrington, E. K. (2005). Abstract and concrete concepts have structurally different representational frameworks. Brain 128, 615-627. https://doi.org/10.1093/brain/awh349

Crutch, S. J., \& Warrington, E. K. (2010). The differential dependence of abstract and concrete words upon associative and similarity-based information: Complementary semantic interference and facilitation effects. Cognitive Neuropsychology 27, 46-71. https://doi.org/10.1080/02643294.2010.491359

Crutch, S. J., Connell, S., \& Warrington, E.K. (2009). The different representational frameworks underpinning abstract and concrete knowledge: Evidence from odd-one-out judgements. The Quarterly Journal of Experimental Psychology 62, 1377-1390. https://doi.org/10.1080/17470210802483834

Delorme, A., \& Makeig, S. (2004). EEGLAB: an open source toolbox for analysis of single-trial EEG dynamics including independent component analysis. Journal of Neuroscience Methods 134(1), 9-21. https://doi.org/10.1016/j.jneumeth.2003.10.009

Dove, G. (2016). Three symbol ungrounding problems: Abstract concepts and the future of embodied cognition. Psychonomic Bulletin \& Review 23, 1-13. https://doi.org/10.3758/s13423-015-0825-4

Dreyer, F. R., Frey, D., Arana, S., von Saldern, S., Picht, T., Vajkoczy, P. \& Pulvermüller, F. (2015). Is the motor system necessary for processing action and abstract emotion words? Evidence from focal brain lesions. Frontiers in Psychology 6, 1-17. https://doi.org/10.3389/fpsyg.2015.01661

Ejerhed, E., Källgren, G., Wennstedt, O., \& Åström, M. (1992). The linguistic annotation system of the Stockholm-Umeå corpus project. Report no. 33, Department of General Linguistics, Umeå University.

Firth, J.R. (1957). A synopsis of linguistic theory 1930-1955. Studies in Linguistic Analysis: 1-32. Reprinted in F.R. Palmer, (Ed.) (1968). Selected papers of J.R. Firth 1952-1959. London: Longman. 
Gilhooly, K. J., \& Logie, R.H. (1980). Age-of-acquisition, imagery, concreteness, familiarity, and ambiguity measures for 1,944 words. Behavior Research Methods and Instrumentation 12, 395-427. https://doi.org/10.3758/BF03201693

Grondin, R., Lupker, S. J., \& McRae, K. (2009). Shared features dominate semantic richness effects for concrete concepts. Journal of Memory and Language 6o, 1-19. https://doi.org/10.1016/j.jml.2008.09.001

Gullick, M.M., Mitra, P., \& Coch, D. (2013). Imagining the truth and the moon: An electrophysiological study of abstract and concrete word processing. Psychophysiology 5o, 431-440. https://doi.org/10.1111/psyp.12033

Harris, Z. (1954). Distributional structure. Word 10, 146-162. https://doi.org/10.1080/00437956.1954.11659520

Holcomb, P. J., Kounios, J., Anderson, J.E., \& West, W.C. (1999). Dual-coding, context availability, and concreteness effects in sentence comprehension: An electrophysiological investigation. Journal of Experimental Psychology: Learning, Memory and Cognition 25, 721-742. https://doi.org/10.1037/0278-7393.25.3.721

Holcomb, P. J., Grainger, J., \& O’Rourke. (2002). An electrophysiological study of the effects of orthographic neighbourhood size on printed word perception. Journal of Cognitive Neuroscience, 14, 938-950. https://doi.org/10.1162/089892902760191153

Jasper, H.H. (1958). Report of the committee on methods of clinical examination in electroencephalography. Electroencephalography and Clinical Neurophysiology 10, 370-375. https://doi.org/10.1016/0013-4694(58)90053-1

Jung, T.-P., Makeig, S., Humphries, C., Lee, T.-W., McKeown, M. J., Iragui, V., \& Sejnowski, T.J. (2000). Removing electroencephalographic artifacts by blind source separation. Psychophysiology 37, 163-178. https://doi.org/10.1111/1469-8986.3720163

Kanske, P., \& Kotz, S.A. (2007). Concreteness in emotional words: ERP evidence from a hemifield study. Brain Research 1148, 138-148. https://doi.org/10.1016/j.brainres.2007.02.044

Kounios, J., \& Holcomb, P.J. (1992). Structure and process in semantic memory: Evidence from event-related brain potentials and reaction times. Journal of Experimental Psychology: General, 121, 459-479. https://doi.org/10.1037/0096-3445.121.4.459

Kounios, J., \& Holcomb, P. J. (1994). Concreteness effects in semantic processing: ERP evidence supporting dual-coding theory. Journal of Experimental Psychology: Learning, Memory, and Cognition 20, 804-823. https://doi.org/10.1037/0278-7393.20.4.804

Kousta, S.-T., Vigliocco, G., Vinson, D.P., Andrews, M., \& Del Campo, E. (2011). The representation of abstract words: Why emotion matters. Journal of Experimental Psychology: General 140, 14-34. https://doi.org/10.1037/aoo21446

Kutas, M., \& Federmeier, K.D. (2000). Electrophysiology reveals semantic memory use in language comprehension. Trends in Cognitive Sciences 4, 463-470. https://doi.org/10.1016/S1364-6613(00)01560-6

Kutas, M., \& Federmeier, K.D. (2011). Thirty years and counting: finding meaning in the N400 component of the Event-Related Brain Potential (ERP). Annual Review of Psychology 62, 621-647. https://doi.org/10.1146/annurev.psych.093008.131123

Kutas, M., \& Hillyard, S.A. (1980). Reading senseless sentences: Brain potentials reflect semantic incongruity. Science 207, 203-205. https://doi.org/10.1126/science.7350657

Laszlo, S., \& Federmeier, L. (2009). A beautiful day in the neighborhood. An event-related potential study of lexical relationships and prediction in context. Journal of Memory and Language 63, 326-338. https://doi.org/10.1016/j.jml.2009.06.004 
Laszlo, S. \& Federmeier, L. (2011). The N400 as a snapshot of interactive processing: evidence from regression analyses of orthographic neighbor and lexical associate effects. Psychophysiology 48, 176-186. https://doi.org/10.1111/j.1469-8986.2010.01058.x

Laszlo, S., \& Federmeier, L. (2014). Never seem to find the time: evaluating the physiological time course of visual word recognition with regression analysis of single-item eventrelated potentials. Language, Cognition and Neuroscience 29, 642-661. https://doi.org/10.1080/01690965.2013.866259

Lau, E. F., Phillips, C., \& Poeppel, D. (2008). A cortical network for semantics: (de)constructing the N400 . Nature Reviews Neuroscience 9, 920-933. https://doi.org/10.1038/nrn2532

Levy, O., Goldberg, Y., \& Dagan, I. (2015). Improving distributional similarity with lessons learned from word embeddings. Transactions of the Association for Computational Linguistics 3, 211-225. https://doi.org/10.1162/tacl_a_00134

Lund, K., \& Burgess, C. (1996). Producing high-dimensional semantic spaces from lexical cooccurrence. Behavior Research Methods, Instruments, \& Computers 28, 203-208. https://doi.org/10.3758/BFo3204766

Mikolov, T., Chen, K., Corrado, G. \& Dean, J. (2013). Efficient estimation of word representations in vector space. arXiv preprint arXiv:1301.3781.

Miller, G.A., \& Fellbaum, C. (1991). Semantic networks of English. Cognition 41, 197-229. https://doi.org/10.1016/0010-0277(91)90036-4

Mårtensson, F., Roll, M., Apt, P., \& Horne, M. (2011). Modelling the meaning of words: neural correlates of abstract and concrete noun processing, Acta Neurobiologiae Experimentalis $71,455-478$.

Mårtensson, F., Roll, M., Lindgren, M., Apt, P., \& Horne, M. (2014). Sensory-specific anomic aphasia following left occipital lesions: Data from free oral descriptions of concrete word meanings. Neurocase 20, 192-207. https://doi.org/10.1080/13554794.2012.741258

Nittono, H., Suehiro, M., \& Hori, T. (2002). Word imageability and N400 in an incidental memory paradigm. International Journal of Psychophysiology 44, 1-11. https://doi.org/10.1016/S0167-8760(02)00002-8

Oldfield, R.C. (1971). The assessment and analysis of handedness: The Edinburgh inventory. Neuropsychologia 9, 97-113. https://doi.org/10.1016/0028-3932(71)90067-4

Paivio, A. (1990). Mental Representations. Oxford: Oxford UP. https://doi.org/10.1093/acprof:oso/9780195066661.001.0001

Paivio, A. (2010). Dual coding theory and the mental lexicon. The Mental Lexicon 5, 205-230. https://doi.org/10.1075/ml.5.2.04pai

Paivio, A., Yuille, J.C., \& Madigan, S.A. (1968). Concreteness, imagery, and meaningfulness values for 925 nouns. Journal of Experimental Psychology 76, Pt.2),1-25. https://doi.org/10.1037/hoo25327

Pexman, P.M., Holyk, G. G., \& Monfils, M.H. (2003). Number-of-features effects and semantic processing. Memory and Cognition 31, 842-855. https://doi.org/10.3758/BF03196439

Pulvermüller, F. (2013). How neurons make meaning: brain mechanisms for embodied and abstract-symbolic semantics. Trends in Cognitive Sciences 17, 458-470. https://doi.org/10.1016/j.tics.2013.06.004

Rabovsky, M., \& McRae, K. (2014). Simulating the N400 ERP component as semantic network error: Insights from a feature-based connectionist attractor model of word meaning. Cognition 132, 68-89. https://doi.org/10.1016/j.cognition.2014.03.010 
Recchia, G., \& Jones, M.N. (2012). The semantic richness of abstract concepts. Frontiers in Human Neuroscience 6, 315. https://doi.org/10.3389/fnhum.2012.00315

Rohde, D.L.T., Gonnerman, L.M., \& Plaut, D.C. (2006). An improved model of semantic similarity based on lexical co-occurrence. Communications of the ACM 8, 627-633.

Roll, M., Mårtensson, F., Sikström, S., Apt, P., Arnling-Bååth, R., \& Horne, M. (2012). Atypical associations to abstract words in Broca's aphasia. Cortex 48, 1068-1072. https://doi.org/10.1016/j.cortex.2011.11.009

Rosch, E., \& Lloyd, B. B. (1978). Cognition and categorization. New Jersey: Lawrence Erlbaum.

Rosch, E., Mervis, C. B., Gray, W.D., Johnson, D. M., \& Boyes-Braem, P. (1976). Basic objects in natural categories. Cognitive Psychology 8, 382-439. https://doi.org/10.1016/0010-0285(76)90013-X

Rugg, M.D. (1985). The effects of semantic priming and word repetition on Event-Related Potentials. Psychophysiology 22, 642-647. https://doi.org/10.1111/j.1469-8986.1985.tbo1661.x

Sabsevitz, D. S., Medler, D.A., Seidenberg, M., \& Binder, J.R. (2005). Modulation of the semantic system by word imageability. NeuroImage 27, 188-200.

https://doi.org/10.1016/j.neuroimage.2005.04.012

Sahlgren, M. (2008). The distributional hypothesis. Rivista di Linguistica 20 (1), 33-53.

Shaoul, C. \& Westbury, C. (2006). Word frequency effects in high-dimensional co-occurrence models: A new approach. Behaviour Research Methods 38, 190-195. https://doi.org/10.3758/BFo3192768

Siakaluk, P., Newcombe, P., Duffels, B., Li, E., Sidhu, D., Yap, M., \& Pexman, P. (2016). Effects of emotional experience in lexical decision. Frontiers in Psychology 7:1157. https://doi.org/10.3389/fpsyg.2016.01157

Szewczyk, J. \& Schriefers, H. (2018). The N400 as an index of lexical preactivation and its implications for prediction in language comprehension. Language, Cognition and Neuroscience 33, 665-686. https://doi.org/10.1080/23273798.2017.1401101

Welcome, S.E., Paivio, A., McRae, K., \& Joanisse, M.F. (2011). An electrophysiological study of task demands on concreteness effects: evidence for dual coding theory. Experimental Brain Research 212, 347-358. https://doi.org/10.1007/s00221-011-2734-8

West, W.C., \& Holcomb, P.J. (2000). Imaginal, semantic, and surface-level processing of concrete and abstract words: an electrophysiological investigation. Journal of Cognitive Neuroscience 12, 1024-1037. https://doi.org/10.1162/08989290051137558

Westbury, C., \& Moroschan, G. (2009). Imageability x phonology interactions during lexical access: Effects of modality, phonological neighbourhood, and phonological processing efficiency. The Mental Lexicon 4, 115-145. https://doi.org/10.1075/ml.4.1.05wes

Westbury, C., Shaol, C., Hollis, G., Smithson, L., Briesemeister, B., Hofmann, M., \& Jacobs, A. (2013). Now you see it, now you don't: on emotion, context, and the algorithmic prediction of human imageability judgments. Frontiers in Psychology 4:991. https://doi.org/10.3389/fpsyg.2013.00991

Westbury, C., Cribben, I., \& Cummine, J. (2016). Imaging imageability: behavioral effects and neural correlates of its interaction with affect and context. Frontiers in Human Neuroscience 10:346. https://doi.org/10.3389/fnhum.2016.00346

Zuccon, G., Koopman, B., Bruza, P., \& Azzopardi, L. (2015). Integrating and evaluating neural word embeddings in information retrieval. In Proceedings ADCS '15, 1-8. https://doi.org/10.1145/2838931.2838936 


\section{Appendix A. Swedish test words belonging to the four semantic categories with English translations}

\begin{tabular}{|c|c|c|c|c|c|c|c|}
\hline \multirow{2}{*}{$\begin{array}{l}\text { Specific } \\
\text { ekorre }\end{array}$} & \multicolumn{3}{|c|}{ General } & \multicolumn{2}{|l|}{ Emotional } & \multicolumn{2}{|l|}{ Abstract } \\
\hline & squirrel & djur & animal & kärlek & love & råd & advice \\
\hline banan & banana & frukt & fruit & glädje & joy & rykte & rumour \\
\hline träd & tree & $v \ddot{x} x t$ & plant & oro & worry & löfte & promise \\
\hline hammare & hammer & verktyg & tool & sorg & sorrow & moral & morale \\
\hline paraply & umbrella & pryl & gadget & lycka & luck & plikt & duty \\
\hline bil & car & fordon & vehicle & $\bmod$ & courage & datum & date \\
\hline bord & table & möbel & furniture & lust & lust & stil & style \\
\hline kvinna & woman & individ & individual & längtan & yearning & svar & answer \\
\hline pistol & gun & vapen & weapon & humor & humour & prestige & prestige \\
\hline plast & plastic & material & material & skräck & horror & mognad & maturity \\
\hline kaffe & coffee & dryck & beverage & tröst & comfort & variation & variety \\
\hline tårta & cake & bakverk & pastry & skam & shame & magi & magic \\
\hline potatis & potato & grönsak & vegetable & $i l s k a$ & anger & visdom & wisdom \\
\hline hus & house & byggnad & building & sjukdom & disease & idé & idea \\
\hline peppar & pepper & krydda & spice & lättnad & relief & ordning & order \\
\hline dator & computer & redskap & tool & chock & shock & position & position \\
\hline majs & corn & gröda & crop & framgång & success & arv & heritage \\
\hline skalbagge & beetle & insekt & insect & hat & hatred & fakta & fact \\
\hline boll & ball & grej & thing & kris & chrisis & term & term \\
\hline soppa & soup & mat & food & förakt & contempt & rutin & routine \\
\hline jeans & jeans & plagg & garment & förälskelse & love & bevis & evidence \\
\hline klocka & clock & instrument & instrument & kaos & chaos & fas & phase \\
\hline flaska & flask & behållare & container & död & death & tendens & tendency \\
\hline mjölk & milk & produkt & product & spänning & excitement & behov & need \\
\hline cykel & bicycle & farkost & vehicle & frihet & freedom & metod & method \\
\hline telefon & telephone & apparat & device & krig & war & brist & lack \\
\hline flygplan & airplane & maskin & machine & skada & harm & fakta & fact \\
\hline elefant & elephant & art & species & njutning & pleasure & mängd & amount \\
\hline tavla & painting & konst & art & problem & problem & avsikt & intention \\
\hline torg & market & plats & place & vänskap & friendship & uppehåll & pause \\
\hline diamant & diamond & smycke & jewelery & svartsjuka & jealousy & tradition & tradition \\
\hline låda & box & förpackning & package & stress & stress & tanke & thought \\
\hline
\end{tabular}




\begin{tabular}{llllllll}
\hline Specific & & General & \multicolumn{3}{c}{ Emotional } & Abstract \\
\hline tallrik & plate & husgeråd & cookware & besvikelse & disappointment & ritual & ritual \\
docka & doll & leksak & toy & depression & depression & reaktion & reaction \\
kärna & kernel & innehåll & content & tacksamhet & gratitude & attityd & attitude \\
papegoja & parrot & organism & organism & passion & passion & överflöd & abundance \\
guld & gold & metall & metal & belöning & reward & tema & theme \\
hjärta & heart & organ & organ & medlidande & pity & gåta & riddle \\
hav & sea & miljö & environment & förtjusning & delight & dröm & dream \\
schack & chess & spel & game & liv & life & lån & loan \\
\hline
\end{tabular}

\section{Appendix B. Pseudowords}

\begin{tabular}{llllllll}
\hline nir & bråll & vorsänta & svand & lömm & seval & darbar & berunnare \\
drigg & åstroskant & midåg & bruska & geno & sep & märno & veol \\
kemp & destuckare & knyp & malpa & ölde & chavars & yna & bik \\
pelkop & trymust & meralde & vuss & topeg & hilem & kerp & grallsick \\
flom & jumbalk & nebanog & tundel & drup & pådir & tjorra & bramid \\
låkdik & omarin & jok & liromed & funner & skjunn & pum & dråv \\
sontes & lotun & hynk & pranbin & frop & bamme & storv & fluna \\
danalod & kråp & bolke & filadonk & plen & bross & perstan & lumang \\
guser & svink & lintes & kirpa & frischor & frädbolt & måver & klåtrin \\
gilerel & spåck & kväng & frim & tålned & ynnalig & spruss & mäklut \\
fripp & skrybbe & dinto & kolanid & presolitur & nalsiped & plarp & brykdrata \\
trinfrut & söldurvig & gocka & pala & tevå & fallin & svåll & skrapp \\
pycklins & vilermål & måsita & dinrom & porden & fiderul & ärste & feglytare \\
hillmak & piltyn & dor & fånna & öri & dragapar & klymbar & gnittrasvup \\
blinna & olanark & fixlan & sjulle & haskar & fostaråg & åmman & bretiflat \\
almsimp & predovås & jopa & gådovinga & halamin & feralev & svack & tropul \\
driska & eming & soms & ird & olk & gara & grungtag & gekvupel \\
engrist & palit & pluderka & kambe & nålda & timla & lis & möndavare \\
kluk & rosir & näms & pät & korm & prug & drem & beklyping \\
vop & knik & fonna & haln & derut & frås & hurapt & svub \\
\hline
\end{tabular}


Appendix C. Imageability-matched SPECIFIC and GENERAL words

\begin{tabular}{|c|c|c|c|c|c|c|}
\hline Swedish & English & Category & Imag & Emo & Freq (SUC) & Syll \\
\hline hav & sea & SPEC & 606 & 427 & 91 & 1 \\
\hline soppa & soup & SPEC & 604 & 170 & 18 & 2 \\
\hline tavla & painting & SPEC & 602 & 259 & 33 & 2 \\
\hline majs & corn & SPEC & 601 & 191 & 6 & 1 \\
\hline guld & gold & SPEC & 594 & 309 & 38 & 1 \\
\hline paraply & umbrella & SPEC & 592 & 237 & 9 & 3 \\
\hline låda & box & SPEC & 591 & 118 & 30 & 2 \\
\hline peppar & pepper & SPEC & 587 & 177 & 3 & 2 \\
\hline torg & market & SPEC & 583 & 209 & 44 & 1 \\
\hline bord & table & SPEC & 582 & 130 & 134 & 1 \\
\hline docka & doll & SPEC & 565 & 214 & 17 & 2 \\
\hline kärna & kernel & SPEC & 542 & 218 & 37 & 2 \\
\hline tallrik & plate & SPEC & 527 & 132 & 11 & 2 \\
\hline plast & plastic & SPEC & 505 & 182 & 22 & 1 \\
\hline bakverk & pastry & GEN & 609 & 227 & 2 & 2 \\
\hline växt & plant & GEN & 605 & 200 & 74 & 1 \\
\hline smycke & jewelery & GEN & 605 & 227 & 8 & 2 \\
\hline grönsak & vegetable & GEN & 598 & 180 & 1 & 2 \\
\hline fordon & vehicle & GEN & 593 & 173 & 24 & 2 \\
\hline farkost & vehicle & GEN & 593 & 173 & 5 & 2 \\
\hline krydda & spice & GEN & 592 & 197 & 8 & 2 \\
\hline möbel & furniture & GEN & 588 & 150 & 20 & 2 \\
\hline frukt & fruit & GEN & 587 & 203 & 25 & 1 \\
\hline insekt & insect & GEN & 586 & 245 & 10 & 2 \\
\hline djur & animal & GEN & 575 & 300 & 218 & 1 \\
\hline dryck & beverage & GEN & 565 & 210 & 30 & 1 \\
\hline behållare & container & GEN & 532 & 118 & 2 & 4 \\
\hline förpackning & package & GEN & 529 & 127 & 10 & 3 \\
\hline
\end{tabular}




\section{Address for correspondence}

\section{Merle Horne}

Department of Linguistics and Phonetics

Lund University

Box 201

S-221 oo Lund

Sweden

merle.horne@ling.lu.se

\section{Co-author information}

Frida Blomberg

Department of Swedish

Linnæus University

frida.blomberg@lnu.se

Mikael Roll

Department of Linguistics and Phonetics Lund University

mikael.roll@ling.lu.se
Johan Frid

Humanities Lab

Lund University

johan.frid@humlab.lu.se

Magnus Lindgren

Department of Psychology

Lund University

magnus.lindgren@psy.lu.se 